\title{
JUDÔ PARAOLÍMPICO: COMPARAÇÕES E RELEXÕES SOBRE AS REALIDADES DE DIFERENTES SELEÇÕES FEMININAS
}

\author{
Mariana Simões Pimentel Gomes, Universidade Estadual de Campinas - UNICAMP, \\ Campinas, São Paulo - Brasil \\ Marcio Pereira Morato, Universidade Estadual de Campinas - UNICAMP, Campinas, São \\ Paulo - Brasil \\ José Júlio Gavião Almeida, Universidade Estadual de Campinas - UNICAMP, Campinas, São \\ Paulo - Brasil
}

\section{RESUMO}

Com o intuito de entender o fenômeno mulheres com deficiência inseridas no esporte paraolímpico, especificamente no Judô, buscamos comparar as realidades de atletas brasileiras e estrangeiras, a partir de uma perspectiva sócio-cultural. Este é um estudo de cunho qualitativo que recorreu à análise de enunciação, uma das técnicas da Análise de Conteúdo para tratamento e interpretação de seus dados. Realizamos entrevistas semi-estruturadas com atletas de seleções nacionais de quatro países diferentes (Brasil, Estados Unidos, Suécia e Inglaterra). As questões de gênero parecem não incomodar as entrevistadas, em relação à deficiência ainda existe certo desconforto e sensação de preconceito alheio, entretanto, o fato de representarem o próprio país tende a inverter a imagem de pessoa em desvantagem para uma atleta de judô com potencialidades, independentemente de sua origem. As realidades analisadas refletem o contexto sócio-cultural das atletas e apontam para suas dificuldades, entretanto, os paradigmas de rótulos e preconceitos quanto ao gênero, deficiência, lutas e alto rendimento estão sendo ressignificados, cada um a seu modo, em consonância com seu contexto cultural.

Palavras-Chave: Direitos da mulher; Artes marciais; Cegueira.

\section{PARALYMPIC JUDO- COMPARISONS AND REFLEXIONS ABOUT THE REALITIES OF DIFFERENT FEMALE TEAMS}

\begin{abstract}
Aiming to understand the phenomenon women with disability in paralympic Sport, especially in judo, we objective to compare the realities of Brazilian and foreigner athletes, from a social cultural perspective. This is a qualitative study that used the enunciation analyses, one of the Contend Analyses techniques for the data treatment and interpretation. We interviewed athletes from four different national teams (Brazil, The United States, Sweden and England) using semi-structured interviews. The gender issues seem not to bother the athletes, in relation to the disability there is still uncomfortable feelings and prejudice positions from others, however the fact of representing their own country tends to invert the image of person in disadvantage to a judo athlete with potentialities, disregarding their origins. The analyzed

Conexões: revista da Faculdade de Educação Física da UNICAMP, Campinas, v. 9, n. 2, p. 85-109, maio/ago. 2011. ISSN: 1983-9030.
\end{abstract}


realities reflect the social-cultural context of the athletes and point out to their difficulties, nevertheless, the label and prejudice paradigms related to gender, disability, martial arts and high performance are being resignificated, each one in its way, according to its cultural context.

Key-Words: Women's rights; Martial arts; Blindness.

\section{JUDO PARALÍMPICO: COMPARACIONES Y REFLEXIONES SOBRE LAS REALIDADES DE DIFERENTES SELECIONES FEMININAS}

\section{RESUMÉN}

Para entender el fenómeno mujeres con discapacidad inseridas en el deporte paralímpico, especialmente en judo, buscamos comparar las realidades de atletas brasileñas e extranjeras, a partir de una perspectiva socio-cultural. Este es un estudio de carácter cualitativo que ha utilizado la análisis de enunciación, una de las técnicas de la Análisis de Contenido para tratamiento e interpretación de sus datos. Realizamos entrevistas semi-estructuradas con atletas de selección nacionales de cuatro países distintos (Brasil, Estados Unidos, Suécia e Inglaterra). Las cuestiones de genero parecen no les molestar a las entrevistadas, en relación a la discapacidad aún existe cierta inquietud y sensación de prejudicio externo, mientras tanto, el hecho de ellas representaren el propio país tiende a invertir el imagen de la persona en desventaja para una atleta de judo con potencialidades, independiente de su origen. Las realidades analizadas reflecten el entorno socio-cultural de las atletas e apuntan para sus dificultades, sin embargo, los paradigmas de estigma y prejudicios cuanto al género, discapacidad, deportes de combate y alto rendimiento están siendo resignificados, cada uno a su manera, de acuerdo con su entorno cultural.

Palabras-Clave: Derechos de la mujer; Artes marciales; Ceguera. 


\section{INTRODUÇÃO}

A fragilidade e submissão da mulher, a diferença e incapacidade das pessoas com deficiência e a brutalidade e agressividade dos esportes de combate, são rótulos que já reinaram na sociedade e que vem se transformando a partir da quebra de paradigmas sociais e comprovações de que a igualdade não depende de gênero ou condição física e para ser aceito socialmente não é necessário aderir somente à determinadas práticas como já ocorreu no passado.

Após vivenciar a rotina de treinamento e preparação pré-competitiva das atletas da Seleção Brasileira de Judô para cegos que participaram dos Jogos Paraolímpicos de Atenas/2004 ocorreu um interesse em caracterizar o grupo sob a perspectiva sócio-cultural, com o intuito de entender quais as dificuldades dessas mulheres no esporte; as razões de sua adesão a uma modalidade de luta; e quais são suas expectativas no movimento paraolímpico, já que estes são grupos extremamente estigmatizados.

Portanto, na perspectiva de entender o fenômeno mulheres com deficiências inseridas no esporte paraolímpico, mais especificamente no Judô, buscamos contextualizar os personagens deste estudo, caracterizando os papéis que a mulher exerceu e ainda exerce na sociedade contemporânea, como se deu seu envolvimento no esporte e quais são as idiossincrasias do judô para pessoas com deficiência visual.

\footnotetext{
1 Mariana Simões Pimentel Gomes atuou como apoio à Comissão Técnica da Seleção Brasileira de Judô Paraolímpico.

Conexões: revista da Faculdade de Educação Física da UNICAMP, Campinas, v. 9, n. 2, p. 85-109, maio/ago. 2011. ISSN: 1983-9030.
} 


\section{A MULHER NO ESPORTE}

Os homens sempre se sentiram seguros em relação à sua imagem perante a sociedade porque sempre viveram num modelo definido por homens, ao invés de um definido pelo sexo oposto. ${ }^{1}$ Seria provável considerarmos essa afirmação como uma verdade que não se aplica aos dias de hoje. Entretanto, ao relembrarmos a história da mulher na sociedade, podemos enxergar significância na fala do autor.

A partir de 1875, quando visivelmente as mulheres passaram a ter menos filhos, por exemplo, a condição feminina melhorou admiravelmente. ${ }^{2}$ Campanhas ativas em prol do sufrágio, expansão da educação secundária para meninas, o direito de sair para o trabalho e de ter profissão possibilitaram uma maior liberdade da mulher em todo o âmbito social.

O esporte de acordo com Hosbawn, ${ }^{2}$ assim como as férias, possibilitou aos jovens (homens e mulheres) encontrarem-se fora dos limites familiares e de casa, pois muitas mulheres da classe média tornaram-se sócias de clubes de turismo e alpinismo. A bicicleta também proporcionou liberdade de movimentos e quebrou os paradigmas em relação à postura das mulheres ao andar a cavalo, além das roupas e corpetes que tinham de usar. O tênis de campo, inventado em 1973, tornou-se favorito entre a classe média, e como em grande parte era praticada por ambos os gêneros, promovia o encontro de filhos e filhas dentro do universo social.

Provavelmente um dos motivos que levaram as mulheres buscarem o esporte foi obter igualdade de oportunidades como resultado das limitações impostas tradicionalmente aos papéis femininos. ${ }^{3}$

Conexões: revista da Faculdade de Educação Física da UNICAMP, Campinas, v. 9, n. 2, p. 85-109, maio/ago. 2011. ISSN: 1983-9030. 
O Movimento Feminista promoveu um questionamento dos verdadeiros papéis sociais e mesmo as mulheres que rejeitavam o feminismo iniciaram a prática esportiva. ${ }^{4}$

A participação em atividades esportivas, além de proporcionar o conhecimento dos limites, das potencialidades e da consciência corporal, também promove oportunidade de autoconhecimento e com isso, de visões, representações sociais ${ }^{5}$ e questionamento de valores. ${ }^{4}$

Dentro de seu universo social a mulher veio ampliando sua gama de possibilidades e determinando seu espaço, no que se refere ao âmbito esportivo e a todas as outras áreas, estabelecendo novas relações com o meio e consigo mesma.

A divisão entre gêneros ainda existe, sendo o envolvimento masculino no esporte ainda maior que o feminino, que vem aumentado a cada ano, com a mulher figurando em quase todas as modalidades esportivas. ${ }^{6}$ Porém, em determinadas modalidades, apesar da existência de categorias femininas, há uma baixa adesão das mulheres devido a uma série de crenças, tabus e paradigmas ainda permanentes na sociedade contemporânea.

Como apresenta Cidade ${ }^{6}$ em 1900, nos Jogos Olímpicos participaram apenas 19 mulheres (1,6 $\%$ do total); em 1984, 1567 mulheres (23\% do total) e em Atenas, 2004 o índice de mulheres participantes bateu recordes ultrapassando a marca dos $40 \%$ (40,6\% do total). De 10,864 atletas, 4412 eram mulheres e 6452 homens.

Conexões: revista da Faculdade de Educação Física da UNICAMP, Campinas, v. 9, n. 2, p. 85-109, maio/ago. 2011. ISSN: 1983-9030. 
Apesar do fato da mulher ter vivenciado inúmeras mudanças de cunho histórico e sócio cultural, sua participação na sociedade ainda está vinculada à questão do paradigma, principalmente se for uma mulher com algum tipo de deficiência ou limitação.

\section{A MULHER NO ESPORTE PARAOLÍMPICO}

A evolução da mulher em relação à sociedade e ao esporte ocorreu também no âmbito paraolímpico, quando esta vertente do esporte teve início em 1948 nos Jogos de Stoke Mandeville. $^{7}$

O crescimento do movimento paraolímpico se evidencia principalmente a partir de Sydney 2000, onde o número de países participantes foi muito maior em relação aos Jogos Olímpicos de Munique, $1972 .^{7}$

Nas paraolimpíadas de Atlanta 1996 o número de participantes foi de 2469 homens $(75,76 \%)$ e 790 mulheres (24,24\%); em 2000 em Sydney, 2891 homens (74,49\%) e 990 mulheres (25,51\%); em Atenas 2004, 2643 homens (69,41\%) e 1165 mulheres (30,59\%); e em Pequim 2008, 2628 homens $(65,52 \%)$ e 1383 (34,48\%) mulheres (IPC, 2009) (Gráfico 1).

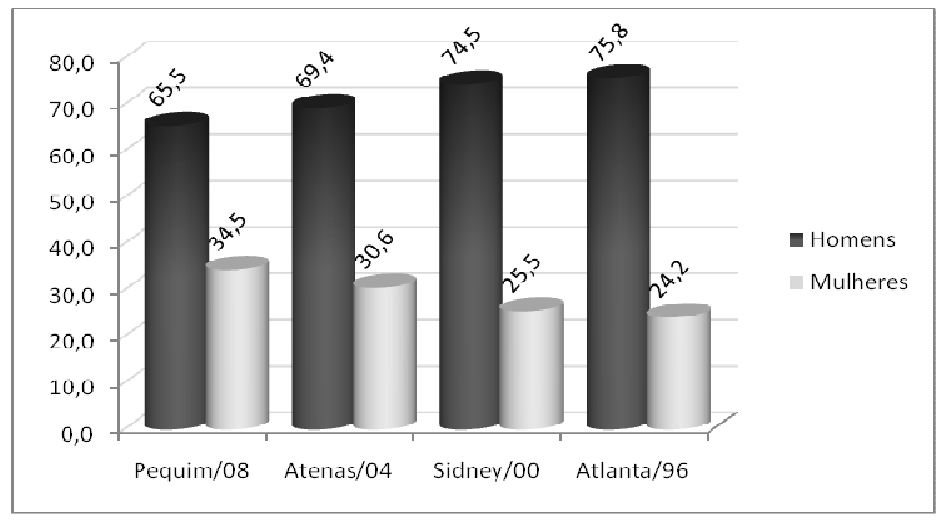

Gráfico 1: Percentuais de participações em paraolímpiadas. Fonte: IPC. ${ }^{15}$

Conexões: revista da Faculdade de Educação Física da UNICAMP, Campinas, v. 9, n. 2, p. 85-109, maio/ago. 2011. ISSN: 1983-9030. 
Podemos visualizar um aumento considerável da participação feminina - média de três pontos percentuais $(3,41 \%)$ por ciclo paraolímpico e diferença de dez pontos percentuais $(10,24 \%)$ de Pequim 2008 para Atlanta 1996 - o que pode demonstrar além da melhora do nível técnico das mulheres, o resultado da política implantada pelo Comitê Paraolímpico Internacional (IPC) no intuito de aumentar a participação feminina nos jogos. ${ }^{8}$

Depauw ${ }^{9}$ apresenta um estudo dirigido pela Canadian Federation of Sport Organizations for the Disabled (Federação Canadense de Organizações de Esporte para Deficientes), cujas informações são baseadas numa investigação feita no próprio país sede, em meninas e mulheres entre os anos de 1986 e 1988. Os resultados apresentados nesse estudo mostram entre outros fatos que o aumento da participação da mulher com deficiência no esporte poderia ocorrer se elas tivessem mais fácil acesso aos locais das práticas de atividades físicas e mais informações sobre o esporte para pessoas com deficiência. Além disso, elas não preferem a segregação por gênero ou por deficiência, mas sim, locais onde a prática de todos possa ser contemplada, independente de suas limitações.

Cidade $^{6}$ afirma que a construção social da deficiência está diretamente relacionada ao estigma e a expectativa. A expectativa pode determinar as diferenças entre as pessoas deficientes e não-deficientes. E o estigma se cria quando certa expectativa ou objetivo não é alcançado.

Quando inserida no meio esportivo a mulher com deficiência amplia suas probabilidades de expectativas passando a fomentar suas possibilidades e não suas limitações. ${ }^{10}$ 
Tendo como exemplo as Paraolimpíadas de 2004, quando observamos a modalidade atletismo, o número de atletas homens e mulheres foi muito aproximado, assim como o número de medalhas obtidas pelos participantes dos dois gêneros. ${ }^{11}$

A delegação brasileira disputou os jogos em Atenas 2004 com 96 atletas dos quais 74 eram homens $(77,1 \%)$ e 22 mulheres $(22,9 \%)$, houve um aumento da participação feminina de $100 \%$ em relação a Sydney-2000. ${ }^{8}$

Já em Pequim 2008 foram 133 homens (71,1\%) e 54 mulheres (28,9\%), quase o dobro do número total de atletas inscritos pelo Brasil nessas duas últimas edições (de 96 para 187). E também um aumento significativo no número de mulheres inscritas pelo país em relação à 2004 (22 para 54) (IPC, 2009) (Gráfico 2).

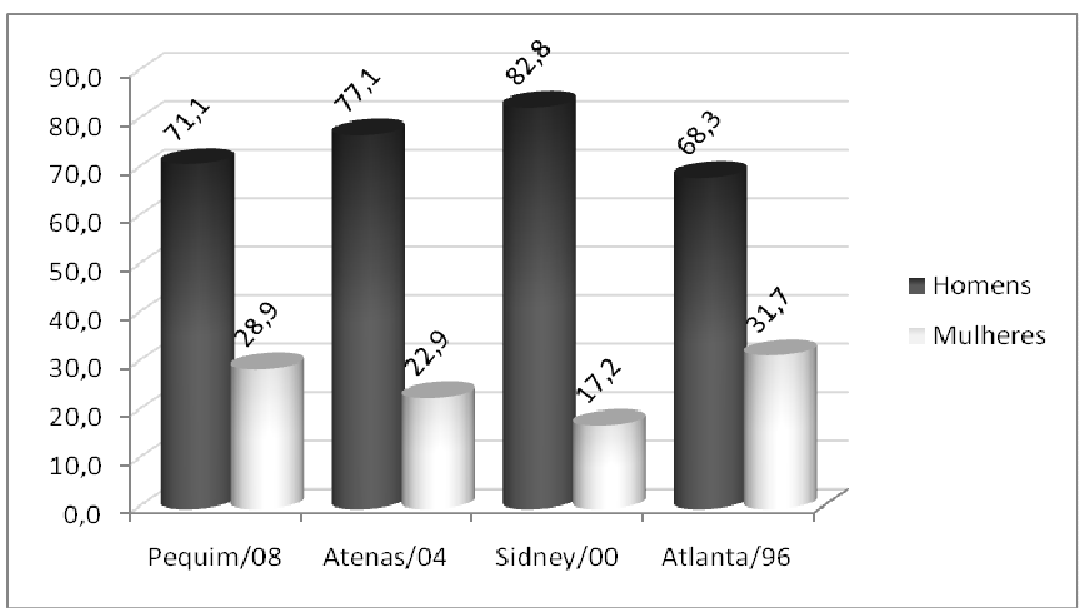

Gráfico 2: Porcentagens de atletas por gênero na delegação brasileira em Paraolimpiadas.

Fonte: IPC. ${ }^{15}$

Por mais que o número de atletas masculinos seja bem superior ao de atletas femininos (quase três vezes maior), o crescimento da participação das mulheres é superior ao de homens quando 
comparados os índices percentuais e não o número de inscrições. De 74 homens em 2004 a 133 em $2008(77,1 \%$ a $71,1 \%)$ e de 22 mulheres a $55(22,9 \%$ a 28,8\%). Observando esses dados podemos perceber que a mulher com deficiência também vem adquirindo seu espaço na sociedade e, consequentemente, no desporto paraolímpico.

\section{JUDÔ PARAOLÍMPICO FEMININO}

O judô foi incluído no programa paraolímpico nos Jogos de Seul, Coréia, 1988. Somente atletas cegos ou com baixa visão, classificados de acordo com a International Blind Sports Federation (IBSA), podem competir. As categorias são divididas por peso, não levando em consideração a classificação visual ${ }^{2}$, logo, os atletas de diferentes classes visuais podem competir juntos.

A categoria feminina foi apresentada pela primeira vez nas Paraolimpíadas de Atenas em 2004, até então apenas atletas homens haviam participado da competição.

As regras nesta modalidade seguem as da Federação Internacional de Judô (FIJ), com algumas adaptações a fim de propiciar maiores condições e possibilidades para os atletas paraolímpicos durante as competições: os atletas não são punidos quando ultrapassam os limites da área de luta; um dos árbitros é encarregado de acompanhar os atletas desde a entrada no tatami, até o centro, onde se deve iniciar a luta; o árbitro também deve conduzir e manter a "pegada" constante entre os participantes, ou seja, durante toda a luta os atletas devem ter contato

\footnotetext{
2 B1 - são os indivíduos que não possuem percepção luminosa em nenhum olho, ou que percebem a luz, mas não podem reconhecer a forma de uma mão a qualquer distância, ou posição; B2 - o indivíduo é capaz de reconhecer a forma de uma mão, até a acuidade visual de 2/60 metros ou um campo visual de um ângulo menor que 5 graus (5 a 10\% da visão); B3 - são os indivíduos que possuem acuidade visual superior a 2/60 metros até aqueles com acuidade visual de $6 / 60$ metros, e ou campo visual maior de 5 graus e menor de 20 graus, (10 à $20 \%$ da visão). ${ }^{12}$
}

Conexões: revista da Faculdade de Educação Física da UNICAMP, Campinas, v. 9, n. 2, p. 85-109, maio/ago. 2011. ISSN: 1983-9030. 
permanente uns com os outros; os atletas B1 são identificados por um círculo vermelho, que é colado em uma das mangas do kimono, na altura dos ombros, para que os árbitros possam direcionar os participantes novamente, se houver separação durante o combate. ${ }^{13-14}$

O Judô foi a modalidade que mais evoluiu de Sydney até Atenas. Dos sete atletas apenas dois (homens) já haviam estado em paraolimpíadas, o que corresponde a $71 \%$ de renovação. $\mathrm{O}$ Brasil foi o $5^{\circ}$ Colocado entre os 26 países participantes, ficando atrás da Alemanha $\left(1^{\circ} \operatorname{com} 9\right.$ atletas), China ( $2^{\circ}$ com 10 atletas), França ( $3^{\circ}$ com 9 atletas) e Espanha ( $4^{\circ}$ com 9 atletas). Duas das medalhas foram conquistadas por mulheres, sendo uma de prata e outra de bronze, enquanto as medalhas masculinas foram uma de prata e outra de ouro. ${ }^{15}$

Em Pequim, 2008, o Brasil obteve a terceira colocação no quadro geral de medalhas de Judô, levando 8 atletas, dos quais 5 mulheres. Em segundo lugar esteve a Rússia, que levou 11 atletas, sendo 6 da categoria feminina. Por fim, a China, país sede, obteve a primeira colocação no quadro de medalhas do Judô, sua equipe contava com 8 atletas, 3 homens e 5 mulheres. ${ }^{16}$ Desta forma, percebe-se que os países que mais conquistaram medalhas paraolímpicas, tinham também maior número de atletas do gênero feminino, o que demonstra o grande espaço que a mulher vem conquistando no esporte e também no Judô paraolímpico.

Neste estudo, utilizando a perspectiva do crescimento da participação feminina no âmbito esportivo, principalmente no movimento paraolímpico, nos questionamos em relação aos interesses das mulheres em praticar um esporte como o judô e a alcançar os níveis de alto rendimento. 
Em um país de muitas desigualdades sociais como o Brasil, vale questionar se as atletas nacionais têm tantas diferenças em relação às atletas de outros países. Inquietações como estas podem facilitar o entendimento, sobre a posição do Brasil na atualidade paraolímpica.

Partindo dessa reflexão da trajetória da mulher no esporte e das evidencias quantitativas do aumento da participação feminina nos eventos paraolímpicos, este estudo busca comparar as realidades vividas por judocas paraolímpicas brasileiras e estrangeiras.

\section{MATERIAIS E MÉTODOS}

Com a delimitação do problema centrada no objetivo exposto anteriormente, as características dessa pesquisa requeriam uma investigação qualitativa de caráter descritivo e analítico. Desta forma, buscamos absorver ao máximo as informações a serem colhidas em relatos orais dos sujeitos, discutindo e analisando seus conteúdos evidentes e latentes. ${ }^{17}$

Para tal, utilizamos a entrevista semi-estruturada ${ }^{18}$ junto a doze atletas pertencentes a quatro distintas seleções (Brasil, Estados Unidos, Inglaterra e Suécia), todas participantes do Campeonato Mundial de Judô Paraolímpico, realizado em julho de 2005 na cidade de São Paulo.

O projeto de pesquisa, com número de protocolo 467/2005, foi aprovado sem restrições pelo Comitê de Ética em Pesquisa da Faculdade de Ciências Médicas da Universidade Estadual de Campinas (CEP/FCM/UNICAMP). Todos os sujeitos consentiram participar da pesquisa e assinaram o Termo de Consentimento Livre e Esclarecido para firmar tal fato.

Conexões: revista da Faculdade de Educação Física da UNICAMP, Campinas, v. 9, n. 2, p. 85-109, maio/ago. 2011. ISSN: 1983-9030. 
As entrevistas foram conduzidas pelos autores do artigo e agendadas previamente com cada entrevistada. Elas foram realizadas no hotel sede da competição durante os períodos de folga das atletas. As judocas estrangeiras foram entrevistadas em inglês. Todas as entrevistas foram gravadas e transcritas para a análise, sendo as de língua estrangeira traduzidas para o português por uma professora de Educação física de naturalidade americana. Entrevistamos 12 atletas no total, sendo que eram oito brasileiras (sendo 2 atletas de classificação visual B1, 3 atletas B2 e 2 atletas B3), duas americanas (B1), uma sueca (B2) e uma inglesa (B1).

De acordo com Laville e Dionne ${ }^{19}$ as perguntas devem ser elaboradas partindo do modo como o pesquisador enxerga o problema, em consonância com as teorias que dispõe. Sendo assim, buscamos trazer a situação problema para a estrutura das perguntas para que pudéssemos racionalizar a problemática, formulando perguntas claras e significativas, viabilizando a pesquisa. Elaboramos perguntas que exploravam aspectos como a qualidade de vida das atletas, suas rotinas de treinamento, seu status dentro da sociedade e o papel que a realidade de seu país pode exercer no seu desenvolvimento na vida esportiva.

Entre os métodos existentes para o tratamento e análise dos dados, é de se considerar adequado o método da Análise de Conteúdo, que Triviños ${ }^{18}$ afirma ser possível aplicar tanto na pesquisa qualitativa como na pesquisa quantitativa, porém com enfoques diferentes.

Para $\operatorname{Bardin}^{20}$ (p. 42), a análise de conteúdo é:

Um conjunto de técnicas de análise das comunicações, visando obter, por procedimentos sistemáticos e objetivos de descrição do conteúdo das mensagens, indicadores (quantitativos ou não) que permitam a inferência de conhecimentos relativos às condições de produção e recepção (variáveis inferidas) destas mensagens.

Conexões: revista da Faculdade de Educação Física da UNICAMP, Campinas, v. 9, n. 2, p. 85-109, maio/ago. 2011. ISSN: 1983-9030. 
O objetivo é descobrir "o que está por trás" dos conteúdos manifestos, dando significado aos conteúdos latentes, que interessam para a pesquisa. As latências podem ser entendidas como os aspectos que permanecem escondidos nas falas, que não se manifestam, estão ocultos, subentendidos, ou ainda, dissimulados nas respostas. Busca-se, assim, selecionar e inferir os aspectos e indicadores que interessam para melhor compreender a temática a ser pesquisada. ${ }^{21}$

Entre as técnicas da Análise de Conteúdo vislumbrada por Bardin, ${ }^{20}$ recorremos à Análise de Enunciação. Esse tipo de análise é complementar à análise temática, que recorta o conjunto das entrevistas através de uma grelha de categorias projetada sobre os conteúdos.

As perguntas geraram um conjunto de temáticas recorrentes, fruto de aspectos latentes encontrados nos discursos dos interlocutores, são elas: PREPARAÇÃO/ TREINAMENTO, RECURSOS SOCIAIS/PESSOAIS (ALIMENTAÇÃO, TRANSPORTE, TRABALHO), PRECONCEITO/ESTIGMA, DIFERENÇAS CULTURAIS.

Após uma primeira análise de todos os discursos (entrevistas) para a determinação das temáticas, realizou-se a inferência individual para que cada discurso fosse novamente analisado em sua singularidade, dentro dos diferentes indicadores (temas) e do sentido atribuído a eles por cada interlocutor.

Esta etapa proporcionou subsídios para a realização da inferência coletiva. Assim, pudemos discutir e refletir sobre os significados de cada temática.

\section{RESULTADOS E DISCUSSÕES}

Perceber como pessoas com deficiência incorporam o esporte é fundamental para que se

Conexões: revista da Faculdade de Educação Física da UNICAMP, Campinas, v. 9, n. 2, p. 85-109, maio/ago. 2011. ISSN: 1983-9030. 
entenda a relação de estigma que elas podem estabelecer com a sociedade. Sentimentos de superação, orgulho, até mesmo, vergonha, podem ser inferidos das falas das atletas.

É diferente para as pessoas verem uma mulher faixa preta, cega no tatame, é bom para eles e para mim (E10 EUA).

Esporte é para todos, todos tem direito de praticar esporte. Nada é impossível. Não gosto muito da separação deficientes/não deficientes... Mas aprecio este tipo de competição, mas também é muito importante treinar e competir com normais (E12 SUE).

O ideal é você ser atleta e não ser atleta do esporte adaptado. A pessoa com deficiência só precisa do esporte adaptado por uma série de questões sócio-culturais. Então ela acaba sendo inserida no processo, tardiamente... Mas o ideal é você ser atleta e competir e treinar com os normais. Não é que você não possa treinar e competir com os deficientes, pode. Mas a sua finalidade é treinar e competir, não procurar treinar com o deficiente, competir com o deficiente (E7 BRA).

Nestes trechos acima as atletas consideram os atletas de judô convencional como normais se colocando numa posição diferente, estigmatizada, expressando o desejo de participarem e competirem com outras pessoas que não apenas com os atletas com deficiência visual. Entretanto, também demonstram sua satisfação em fazer parte dessa camada, pois se sentem úteis, produtivas, considerando o processo de treinamento em detrimento dos resultados da competição.

Identificamos também os discursos que super valorizam o esporte adaptado, colocando-o como responsável pela mudança de paradigmas em relação às pessoas com deficiência, fazendo com que elas possuam vida social ativa, percam a "vergonha" de sair de casa e mostrar sua deficiência.

A minha vida eu não sei como seria, a vida pra tantas pessoas, né, não poderem praticar esporte, então eu acho que essa coisa do desporto adaptado veio, assim, pra melhorar muitas e muitas coisas. Dar uma melhor qualidade de vida para as pessoas. Ajudar muito na questão da saúde, em vários aspectos... (E1 BRA).

Acho que é uma maravilha, né? Porque antigamente o deficiente ficava só dentro de casa, escondidinho, que até a família tinha vergonha, né? E hoje em dia o pessoal fazendo esporte, né? Mostrando pra todo mundo, saindo de suas cidades, seus

Conexões: revista da Faculdade de Educação Física da UNICAMP, Campinas, v. 9, n. 2, p. 85-109, maio/ago. 2011. ISSN: 1983-9030. 
estados, até de seu país, pra mostrar o esporte adaptado. Acho que isso é fantástico, maravilhoso! (E6 BRA).

A prática do esporte não só "tira de casa" as pessoas com deficiência, mas também contribui para a autonomia dessas pessoas, que passam a se sentir confiantes, seguras para realizar determinados tipos de tarefas que não faziam antes. Seu comportamento muda, suas razões para sair de casa se modificam e aí fatores como a qualidade de vida passam a ser conhecidos e valorizados.

Encontramos aqueles discursos que se referem ao esporte adaptado como nada de diferente em suas vidas, atletas essas que não se consideram deficientes, nem vêem influências significativas do esporte em suas vidas. No que tange a questão da deficiência visual e o esporte paraolímpico, elas treinam com pessoas videntes e não avaliam, ou tentam não avaliar sua deficiência visual como um estigma.

Olha, eu não me sinto uma atleta adaptada, não. Me sinto tão atleta quanto os olímpicos. A minha pequena deficiência na hora do tatame é como se não fosse nada (E3 BRA).

Olha, eu treino com vidente, então significa totalmente nada. Significa que eu tenho um pouco, o quê? Meu reflexo é um pouco menor, eu preciso então começar já pegando, mas como a minha deficiência não é tão grave assim, não faz muita diferença (E4 BRA).

Pra mim é uma coisa diferente. Porque sempre vivi entre pessoas... nunca tinha convivido com pessoas, assim, deficientes. Minha vida sempre foi normal, tudo, por exemplo, hoje foi diferente porque eu vi o pessoal, assim, que mora perto de casa, tudo, entendeu? Então para eles é diferente "ver eu" no meio deles (os atletas cegos ou com DV [Deficiência Visual]). Aí... aí é diferente pra mim. Agora quando eu estou no meio deles, é... pra mim é normal. Só é diferente quando vêm algumas pessoas que não estão acostumadas. Só é diferente por causa delas (E5 BRA).

Falar de si mesma e de sua sensação em relação às palavras "atleta adaptada" pode depender da classificação visual no caso das entrevistadas, pois se essas atletas são classificadas como B3, a deficiência visual parece não interferir em demasia nas suas vidas. Antes do judô já eram independentes, trabalhavam ou estudavam, já se preocupavam com a referenciada 
qualidade de vida. Diferentemente dos outros discursos que se referem à prática do judô como um determinante na mudança das rotinas de vida das entrevistadas categorias B1 e B2.

Em relação às dificuldades, os discursos das atletas brasileiras em geral se focaram na falta de recurso e apoio financeiro público e privado, o que gera dificuldade de obtenção de uma alimentação adequada bem como condições de treino apropriadas para aperfeiçoar o desempenho nas competições. As atletas declaram ter dificuldade em conciliar as atividades, pois não tendo dinheiro suficiente para fazerem do esporte sua profissão efetiva, têm de trabalhar para conseguir treinar adequadamente e também comprar os materiais e suplementos necessários para o treinamento.

É muito... para você ser uma boa atleta, você teria que ter uma alimentação, assim, bastante é... variada, tudo. Só que não tendo nenhum tipo de verba à disposição, fica difícil realmente ter esse tipo de coisa, né, ao alcance (E1 BRA).

Neste trecho uma das entrevistadas fala do fator alimentação que deriva da falta de incentivo, o que não acontece com as atletas de outros países nos quais as dificuldades não se relacionam ao dinheiro. No Brasil, sabemos que muitas pessoas realmente não têm acesso à variedade de nutrientes necessária numa refeição, geralmente se come o que há disponível e no caso dessas atletas, que declaram pertencer a classes sociais como essas, o volume e intensidade de treinamento indicados para atletas de alto rendimento não podem ser suportados por uma alimentação defasada.

Para as atletas dos outros países esse problema parece não acontecer, pois relatam dificuldades divergentes em relação as nossas.

Me "candidatei" para receber uma quantia que as pessoas dedicam para atletas com deficiência visual. A minha mãe e a minha família ajudam bastante, mas também recebo de outras organizações. (E12 SUE).

Conexões: revista da Faculdade de Educação Física da UNICAMP, Campinas, v. 9, n. 2, p. 85-109, maio/ago. 2011. ISSN: 1983-9030. 
Esta atleta relata que em seu país existem organizações que apóiam as pessoas com deficiência, e sua família também lhe oferece os subsídios necessários para suportar a rotina de treinamento do esporte de alto rendimento.

Principalmente no Brasil pudemos perceber que a classe social das atletas também influenciou nos seus discursos.

Só meu pai que ta trabalhando, né, então é bem difícil... (E1 BRA).

Porque tem que treinar de manhã e trabalhar à noite para poder conseguir uma "grana" para poder manter os treinos (E3 BRA).

A dificuldade, por quê? Porque não tem apoio, não tem muito apoio. Que nem esse ano ninguém recebeu nada, sabe. Não dá apoio para o atleta, sabe? Tem atleta aí que acaba parando até de fazer judô porque não tem nenhum apoio financeiro... Eu acho errado isso (E5 BRA).

Primeiro que no Brasil, o pessoal acha que atleta é serviço de vagabundo, né? Que não tem o que fazer, vai ser atleta, né? E a gente não tem muito incentivo, nem com material pra gente ta treinando, equipamento, sala pra gente ter uma... um bom dojô. Um local pra você ta fazendo uma academia e alimentação. Se você não tiver uma família que pode, que te dê uma alimentação legal, você fica mais defasado. Você sempre chega lá meio cansado, meio desanimado (E6 BRA).

Às vezes eu tenho que depender da minha mãe e do meu pai pra poder treinar (E8 BRA).

As atletas acima demonstram precisar do apoio e de incentivos para poder prosseguir na carreira esportiva. Também afirmam sentirem-se inferiorizadas quando dizem que sua profissão é ser atleta. A partir de seus discursos inferimos que não podem depender dos recursos de suas famílias, apenas do trabalho, ou eventualmente de patrocínio.

Porém, o fato de serem do alto rendimento parece não contar para a aquisição do patrocínio, pois o esporte paraolímpico ainda está em desenvolvimento e os investimentos em torno dessa camada dependem da propaganda e divulgação da mídia, fato que tem ocorrido timidamente.

Conexões: revista da Faculdade de Educação Física da UNICAMP, Campinas, v. 9, n. 2, p. 85-109, maio/ago. 2011. ISSN: 1983-9030. 
Duarte e Santos ${ }^{22}$ afirmam que muitas pessoas com deficiência são de classes sociais carentes. Logo, se essas pessoas se tornam atletas e não recebem apoio financeiro para se dedicarem a sua carreira, sua realidade se mantém e a possibilidade de perseverança desses indivíduos no esporte vai se minimizando. Podemos confirmar estes fatos nos discursos de muitos atletas que foram medalhistas em paraolimpíadas e relatam que mesmo após retornarem de competições reconhecidas, suas condições de treino, alimentação e vida de atleta continuaram dificultadas por falta de respaldo, não só de órgãos institucionais, como da população do país em geral, que normalmente não se aproxima do esporte paraolímpico, visto que este começou a ser mais difundido pela mídia nas Paraolimpíadas de Atenas, 2004.

No discurso das seguintes atletas pudemos notar que suas condições financeiras são mais estáveis e podem dar o respaldo necessário para o treinamento adequado sugerido pelos técnicos da seleção brasileira.

\footnotetext{
Não recebo nenhum tipo de apoio. Meus pais mesmo e bolsa da Iniciação científica na faculdade. Dificuldade? É... no meu caso, especificamente no meu caso é mais conciliar tudo (E4 BRA).

Acho que a maior dificuldade realmente é o tempo... É... como eu já falei antes, eu tenho uma vida, uma agenda muito densa e muitas vezes é difícil ir treinar. Eu me mantenho só com o meu trabalho. $\mathrm{O}$ desporto não me ajuda financeiramente (E7 BRA).
}

Entretanto, durante as entrevistas ambas mostraram estar cientes de que são exceções no meio do esporte paraolímpico, mais especificamente no judô, além de deixarem explícita a necessidade de apoio e incentivo para que pudessem se dedicar exclusivamente para o esporte.

$\mathrm{Na}$ tentativa de extrair das falas das atletas quais as dificuldades enfrentadas por mulheres que praticam a modalidade e o que significa para elas fazer parte da camada do esporte adaptado de alto rendimento, percebemos que as dificuldades são características dos países 
entrevistados e dependem das condições sociais das atletas, bem como da relação de desenvolvimento do país em que elas vivem.

No Brasil as atletas mostraram que sua maior dificuldade é a falta de apoio e de incentivo financeiro, o que faz com que a prática do judô não seja levada como uma profissão, pois elas precisam estudar e trabalhar para poderem arcar com suas despesas, bem como com as despesas exigidas pelo treinamento adequado que abrangem alimentação, academia, materiais e suplementos.

As atletas brasileiras que não se queixaram de dinheiro são aquelas que possuem uma condição financeira mais estável. Seus pais financiam suas despesas ou elas mesmas trabalham e conseguem conciliar suas atividades, embora essa seja sua maior reclamação. Percebemos aí a necessidade do apoio novamente, para que elas pudessem se dedicar apenas para o esporte ${ }^{3}$.

No discurso das atletas estrangeiras notamos que as dificuldades não necessariamente tangem a questão financeira, mas sim as características culturais de cada país. Nos Estados Unidos, por exemplo, uma das atletas relatou dificuldade para manter o peso da categoria no judô, afirmando que fazer dieta é um grande sacrifício. Isso exemplifica um grande contraste social, pois mais de uma atleta brasileira considerou a alimentação inadequada fator crucial para seu desenvolvimento no esporte, enfatizando a má qualidade de sua alimentação estar relacionada à falta de dinheiro.

\footnotetext{
${ }^{3}$ A pesquisa foi realizada durante o processo de implementação da bolsa-atleta, naquele momento apenas os atletas que tinha participado dos Jogos Paraolímpicos de Atenas possuíam um bolsa do Comitê Paraolímpico Brasileiro. Em 2004 o projeto para incentivo ao esporte de alto rendimento foi aprovado e a partir daí iniciou-se o encaminhamento dessas ações. Para maiores informações consultar: http://www.esporte.gov.br/snear/bolsaAtleta/default.jsp
}

Conexões: revista da Faculdade de Educação Física da UNICAMP, Campinas, v. 9, n. 2, p. 85-109, maio/ago. 2011. ISSN: 1983-9030. 
Tem que controlar o peso, fazer dieta e ser muito disciplinada. Você quer sair, fazer alguma coisa, mas tem que treinar. Você tem que decidir o quanto quer se sacrificar. (E10 EUA).

Verificamos também fatores como transporte, disciplina, falta de mulheres com deficiência treinando como dificuldades dessas atletas estrangeiras, o que ressaltou ainda mais os contrastes com o Brasil.

Nos trechos abaixo temos exemplos destes contrastes nos discursos das atletas estrangeiras. Elas enfatizam suas dificuldades ressaltando características marcantes de seu ambiente social.

Transporte... chegar no treino na hora, acaba atrasando e não pode ir andando. Sempre é necessária a ajuda de alguém para guiar e levar aos lugares. (E9 ING).

Acima a atleta tenta explicar como se sente no metrô numa cidade altamente urbanizada da Inglaterra, onde transita um fluxo extremamente alto de pessoas, o que prejudica sua locomoção sozinha e impede que ela consiga chegar aos locais de treino nos horários estabelecidos.

Na Suécia têm aproximadamente 17 mil judocas, mas na maioria são crianças. Eu sou a única DV que compete... Me sinto muito sozinha. Eles tiveram que pesquisar muito para saber a melhor maneira de me treinar. (E12 SUE).

Esta atleta relata que sua maior dificuldade é não ter com quem treinar e, pelo menos no meio que se insere, o tema parece ser algo novo, que requer estudos para que possa ser aplicado. Isso demonstra mais um contraste em relação ao Brasil que no âmbito da pesquisa acadêmica vem ampliando o leque de estudos ao redor do esporte paraolímpico em geral.

Quando falamos da sensação de representar seus países como atletas do esporte adaptado, as respostas não dependeram necessariamente do país de origem ou de condições sociais. Além disso, quando perguntamos sobre seu futuro no esporte de competição, a maioria respondeu 
ter ambições de ir a paraolimpíada de Pequim 2008. Das 12 (doze) atletas entrevistadas, 5 (cinco) participaram dos Jogos Paraolímpicos de Pequim. Deste total, 4 (quatro) atletas são brasileiras e 3 (três) conquistaram medalhas para o Brasil.

\footnotetext{
Eu acho demais, representar os EUA. (E10 EUA).

É bom pensar que sou uma das primeiras mulheres... Eu penso: "eu fiz", "eu consegui”. (E9 ING).

Me sinto orgulhosa, tenho medo de envergonhar meu próprio país, é uma honra... (E12 SUE).

É inexplicável, sabe? Já estar competindo da maneira que eu estou competindo, pô? Ser campeã! A "parada” é muita coisa. Não tem explicação ainda. Estou tentando me acostumar com a idéia. (E4 BRA).
}

Ai, eu me sinto até orgulhosa! Eu sou bem patriota (E8 BRA).

Sentimentos como honra, orgulho, responsabilidade e excitação em representar o próprio país, são evidentes e demonstra a vontade de se exibir de onde vem, qual sua identidade, sua bandeira, sua pátria, independente das condições que ela oferece para o desempenho de seus atletas nas competições.

Percebemos que as questões relacionadas ao estigma e preconceito social ainda estão presentes nos discursos das atletas, porém não se ligam exclusivamente ao fato de serem mulheres, ou deficientes, praticantes de um esporte de combate ou atletas de alto rendimento. Cada atleta enxerga seu papel na sociedade de forma diferente, contudo, esses papéis se assemelham à medida que se referem às suas rotinas de vida e ao meio ao qual pertencem.

\section{CONSIDERAÇÕES FINAIS}

Este estudo buscou comparar as realidades de judocas brasileiras e estrangeiras com um olhar em seu perfil sócio-cultural, considerando todo o estigma que há em ser mulher, na condição

Conexões: revista da Faculdade de Educação Física da UNICAMP, Campinas, v. 9, n. 2, p. 85-109, maio/ago. 2011. ISSN: 1983-9030. 
de deficiência, praticante de um esporte de combate no alto rendimento.

O contraste da seleção brasileira com as outras seleções é explicito e se dá principalmente pelos contextos sociais analisados. Inicialmente, as diferenças culturais entre um país em desenvolvimento como o Brasil e países já desenvolvidos Inglaterra, Suécia e Estados Unidos determinam a divergências de discurso, no que tange às rotinas de treinamento, necessidades financeiras, contingente de pessoas com deficiência.

As questões de gênero parecem não incomodar as entrevistadas, porém nos casos de atletas de classificação visual B1 (cegas), nota-se que a deficiência ainda gera desconforto e sensação de preconceito alheio, entretanto, o fato de representarem o próprio país as torna mais capazes de exercerem seu papel na sociedade, invertendo a imagem de pessoa em desvantagem para uma atleta de judô com potencialidades, independentemente de sua origem.

As realidades analisadas refletem o contexto sócio-cultural das atletas e apontam para suas dificuldades enquanto pertencentes da camada do esporte paraolímpico profissional. De todas as maneiras, fica claro que os paradigmas de rótulos e preconceitos quanto ao gênero, deficiência, lutas e alto rendimento estão sendo ressignificados, cada um a seu modo, em consonância com seu contexto cultural.

\section{REFERÊNCIAS}

${ }^{1}$ ANDERSON, J. E. Women and sport psychology: an applied perspective. In: PUHL, J.; BROWN, C. H.; VOY, R. O. (Eds.). Sport science perspectives for women. Colorado: Springer, 1985.

Conexões: revista da Faculdade de Educação Física da UNICAMP, Campinas, v. 9, n. 2, p. 85-109, maio/ago. 2011. ISSN: 1983-9030. 
${ }^{2}$ HOBSBAWM, E. A nova mulher. In: HOBSBAWM, E (Org.). A Era dos impérios. Rio de Janeiro: Paz e Terra, 1988.

${ }^{3}$ DUNNING, E. Sport matters: sociological studies of sport violence and civilization. London: Routledge, 1999.

${ }^{4}$ ALONSO, L. K. Mulher, corpo e mitos no esporte. In: SIMÕES, A. C. (Org.). Mulher e esporte mitos e verdades. São Paulo: Manole, 2003.

${ }^{5}$ LANE, S. T. M. Usos e abusos do conceito de representação social. In: SPINK, M. J. (Org.). O conhecimento do cotidiano. São Paulo: Brasiliense, 1993.

${ }^{6}$ CIDADE, R. Atletas paraolímpicas: figurações e sociedade contemporânea. 2004. 248 f. Tese (Doutorado em Educação Física) - Faculdade de Educação Física, Universidade Estadual de Campinas, Campinas, 2004.

${ }^{7}$ STEFANE, C. et al. Esporte adaptado, Paraolimpíadas e Olimpíadas Especiais. In: DACOSTA (Org.). Atlas do esporte no Brasil. Rio de Janeiro: Shape, 2005. p. 645-649.

${ }^{8}$ COSTA, A. M. Relatório da chefia de delegação. In: COMITÊ PARAOLÍMPICO BRASILEIRO. Relatório geral. Brasília, 2005.

${ }^{9}$ DEPAUW, K.; GAVRON, S. J. Disability and sport. Champaign: Human Kinetics, 1995.

Conexões: revista da Faculdade de Educação Física da UNICAMP, Campinas, v. 9, n. 2, p. 85-109, maio/ago. 2011. ISSN: 1983-9030. 
10 AMARAL, L. Deficiência: questões conceituais e alguns de seus desdobramentos. Cadernos de Psicologia da USP, n. 1, 1996. p. 3-12.

${ }^{11}$ OLIVEIRA FILHO, C. W. Relatório da equipe paraolímpica de atletismo brasileira nos XII Jogos Paraolímpicos de Atenas. In: COMITE PARAOLIMPICO BRASILEIRO. Relatório geral. Brasília, 2005.

12 CONFEDERAÇÃO BRASILEIRA DE DESPORTOS PARA CEGOS (CBDC). Classificação visual. Disponível em: http://www.cbdc.org.br/novo_site/index.php?idmenu=26\&codtipoconteudo=4>. Acesso em: 26 set. 2009.

${ }^{13}$ BENITO, J. Nuevas tecnologias aplicadas a los deportes para ciegos y deficientes visuales. Barcelona: Espanha, 1996.

14 INTERNATIONAL BLIND SPORTS FEDERATION (IBSA). Judo. Disponível em: $<$ http://www.ibsa.es/eng/deportes/judo/presentacion.htm>. Acesso em: 20 out. 2009.

${ }^{15}$ MATARUNA, L. et al. Analysing the brazilian judo team participation in the Athens Paralympic Games. In: EUROPEAN COLLEGE OF SPORTS SCIENCE CONGRESS, 2005, Belgrado. Poster Sessions. Belgrado: ECSSC, 2005.

16 INTERNATIONAL PARALYMPIC COMMITTEE (IPC). Results. Disponível em: <http://www.paralympic.org/Sport/Results/>. Acesso em: $10 \mathrm{dez} .2009$.

Conexões: revista da Faculdade de Educação Física da UNICAMP, Campinas, v. 9, n. 2, p. 85-109, maio/ago. 2011. ISSN: 1983-9030. 
${ }^{17}$ THOMAS, J. R.; NELSON, J. K. Métodos de pesquisa em atividade física. Porto Alegre: Artmed, 2002.

${ }^{18}$ TRIVIÑOS, A. N. S. Introdução à pesquisa em ciências sociais: a pesquisa qualitativa em educação. São Paulo: Atlas, 1987.

${ }^{19}$ LAVILlE, C.; DIONNE, J. A Construção do saber: manual de metodologia da pesquisa em ciências humanas. Porto Alegre: Artes Médicas Sul, 1999.

${ }^{20}$ BARDIN, L. Análise de conteúdo. Lisboa: Edições 70, 1977.

${ }^{21}$ BALBINO, H. Pedagogia do treinamento: método, procedimentos pedagógicos e as múltiplas competências do técnico nos jogos desportivos coletivos. 2005. Tese (Doutorado em Educação Física) - Faculdade de Educação Física, Universidade Estadual de Campinas, Campinas, 2005.

${ }^{22}$ DUARTE, E.; SANTOS, T. P. Adaptação e inclusão. In: DUARTE, E.; LIMA, S. M. Atividade física para pessoas com necessidades especiais: experiências e intervenções pedagógicas. Rio de Janeiro: Guanabara Koogan, 2003.

Conexões: revista da Faculdade de Educação Física da UNICAMP, Campinas, v. 9, n. 2, p. 85-109, maio/ago. 2011. ISSN: 1983-9030. 